\title{
ANÁLISE DO FLUXO DE VALOR DA PRODUÇÃO DE IOGURTE EM UMA EMPRESA DE LATICÍNIOS NA ZONA DA MATA/MG
}

\section{YOGURT VALUE STREAM MAPPING IN A DAIRY COMPANY IN THE ZONA DA MATA/MG}

\section{BENINI ${ }^{1, *}$ e A. F. BONOTO ${ }^{1}$}

${ }^{1}$ Universidade Federal de Viçosa, Departamento de Engenharia de Produção e Mecânica, Viçosa, Minas Gerais, Brasil

*Autor correspondente. Universidade Federal de Viçosa, Departamento de Engenharia de Produção e Mecânica, Viçosa, Minas Gerais, Brasil, Phone: +55 31 36126500

Endereço de e-mail: lucasbenini@gmail.com (L. Benini).

\begin{tabular}{l} 
A R T I C L E I N F O \\
\hline Article history: \\
Received 2018-10-20 \\
Accepted 2018-12-21 \\
Available online 2019-12-20 \\
pa l a vra s-chave \\
Lean manufacturing \\
Desperdícios \\
Laticínio \\
Iogurte \\
ke yw o r ds \\
Lean manufacturing \\
Waste \\
Dairy product \\
Yogurt
\end{tabular}

\begin{abstract}
R E S U M O
O lean manufacturing visa a minimização dos desperdícios na manufatura de determinado produto. Este trabalho tem como objetivo identificar os desperdícios abordados pelo lean manufacturing que ocorrem na linha de produção do iogurte em uma empresa de laticínios na Zona da Mata/MG. Para tanto, foi realizada a análise do fluxo de valor, elaborando-se o mapa do fluxo de valor e identificando-se os desperdícios. Posteriormente foi construído o mapa de estado do estado futuro. Foram identificados 5 tipos de desperdícios e apresentadas propostas de melhorias para reduzi-los. Com a implementação destas melhorias, pode-se reduzir em torno de $60 \%$ do tempo de atividades que não agregam valor e $55 \%$ do lead time de produção do iogurte.
\end{abstract}

\section{A B S T R A C T}

Lean manufacturing aims to the waste minimization in product manufacturing. This article aims to identify the lean manufacturing processes that occur in the yogurt production line at a dairy company in the Zona da Mata / MG. For this purpose, a value stream mapping was elaborated and the wastes were identified. Subsequently, the future state map was built. Five wastes type were identified and improvements were proposed in order to reduce these wastes. With these improvements, the time for activities that do not add value can be reduced by $60 \%$ and by $55 \%$ the yogurt lead time. 


\section{INTRODUÇÃ̃O}

No cenário econômico atual a necessidade das empresas de se manterem competitivas cresce cada vez mais, impulsionando as tentativas de se obter vantagem sobre os concorrentes dentro do mercado regional. Neste contexto, o lean manufacturing é uma alternativa considerável para esta necessidade.

Womack e Jones (1992) definem o lean manufacturing (ou manufatura enxuta) como uma abordagem que busca uma forma de melhor organizar e gerenciar os relacionamentos de uma empresa com seus clientes, cadeia de fornecedores, desenvolvimento de produtos e operações de produção; para que seja possível produzir cada vez mais com menos recursos (equipamentos, mão-de-obra, tempo). Com este intuito, o pensamento enxuto visa eliminar atividades de produção que não agregam valor ao produto final, para reduzir o custo de produção do mesmo. Para identificar tais atividades, parte-se do princípio de que tudo que não é necessário para se atender exatamente o que o cliente deseja, é considerado desperdício. Os desperdícios abordados pelo lean manufacturing são: perda por superprodução, perda por espera, perda por transporte excessivo, perda no processamento em si, perda por estoque, perda por movimentação desnecessária e perda por produção de produtos defeituosos.

O pensamento enxuto (lean thinking) pode ser aplicado nos mais diversos setores. Nazareno (2003) efetuou uma pesquisa sobre o desenvolvimento e aplicação de um método para implementar sistemas de produção enxuta, e em virtude da grande dificuldade de implantação de sistemas de produção enxuta fora da indústria automobilística, ele sugeriu como desenvolvimentos futuros alternativas complementares de mapeamento e análise do fluxo de valor para empresas que apresentem uma ampla gama de produtos. Silva e Santos (2004) analisaram a aplicação dos conceitos da produção enxuta em uma empresa prestadora de serviços. Imtiaz e Ibrahim (2007) buscaram alavancar a produção de uma empresa do setor de construção civil ao implementar ferramentas do pensamento enxuto. Kappes (2011) conseguiu implementar conceitos da manufatura enxuta em uma empresa do setor metal-mecânico.

Um setor que também pode se beneficiar do pensamento enxuto é o alimentício. Neste setor, na maioria dos casos, a matéria prima e o produto final são perecíveis e, portanto, possuem um período de validade muito curto quando comparado a outros setores. Uma empresa que possui destaque no setor alimentício se localiza na Zona da Mata/MG. Recentemente esta empresa transferiu sua estrutura fabril para um local com melhor infraestrutura - estrutura devidamente projetada para aumentar a sua capacidade de produção - visto que um dos gargalos de produção identificado na época, era a incapacidade de suprir a demanda devido à pequena capacidade de produção da fábrica. Com a nova estrutura, a empresa de laticínios busca continuamente a redução de seus desperdícios e o aumento da produtividade. Atualmente oferece em sua gama de produtos: leite, doce de leite, manteiga, queijo, requeijão e iogurte. O produto que, de acordo com os atuais gestores, apresenta maiores desperdícios em sua cadeia de produção é o iogurte. Desta forma, devem-se, portanto, identificar os gargalos de produção para contribuir para uma melhor produtividade do mesmo.

O objetivo deste trabalho é identificar os desperdícios presentes na cadeia de produção do iogurte de uma empresa do setor de laticínios e propor melhorias, a fim de eliminar ou reduzir os desperdícios abordados pelo lean manufacturing.

\section{PRINCÍPIOS DA MANUFATURA ENXUTA}

O Pensamento Enxuto é baseado em cinco princípios (Womack, 1998; Womack e Jones, 2004):

Valor: a produção enxuta busca eliminar as fontes de desperdício e criar valor. O ponto de partida essencial para o pensamento enxuto é o valor. $\mathrm{O}$ valor só pode ser definido pelo cliente final, caso contrário, corre-se o risco de fornecer eficientemente para o cliente algo que ele não deseja. Por sua vez, este só é significativo quando expresso em termos de um produto específico, bens e serviços, que atendam às necessidades do cliente a um preço característico em um momento específico. Do ponto de vista do cliente, é para isso que os produtores existem, portanto, o valor é criado pelo produtor.

Fluxo de valor: o fluxo de valor é o conjunto de todas as ações específicas necessárias para se levar um produto específico (seja ele um bem, um serviço, ou, cada vez mais, uma combinação dos dois) a passar pelas três tarefas gerenciais críticas em qualquer negócio: a tarefa de solução de problemas que, vai da concepção até o lançamento do produto, passando pelo projeto detalhado e pela engenharia, a tarefa de gerenciamento da informação, que vai do recebimento do pedido até a entrega, seguindo um detalhado cronograma, e a tarefa de transformação física, que vai da matéria-prima ao produto acabado nas mãos do cliente.

Fluxo: depois de especificar o valor, mapear o fluxo de valor e eliminar as atividades que não agregam valor, o próximo passo no pensamento enxuto consiste em fazer fluir as atividades que criam valor. Buscar-se-á alcançar o fluxo contínuo como um dos objetivos mais importantes da produção enxuta. O fluxo especifica a movimentação tanto do material a ser processado quanto de informações relacionadas a produção, compra e venda.

Sistema puxado: na produção puxada um processo somente será acionado quando o processo seguinte solicitar. $\mathrm{O}$ objetivo é construir um processo para fazer somente o que o próximo processo necessita e quando necessita, em outras palavras, o cliente é quem deve puxar o produto, puxar a produção e puxar o valor. Caso contrário, os processos fornecedores tenderão a fazer o que os processos clientes não precisam naquele momento, levando com essa prática, ao excesso de produção, à formação de estoques, à produção empurrada e, enfim, ao desperdício.

Perfeição: à medida em que os princípios anteriores sejam alcançados, ocorrerá a todos os envolvidos que, as oportunidades de redução de esforço, de erro, de espaço, de tempo e de custo são infinitas, possibilitando à empresa oferecer um produto que se aproxima cada vez mais do que o cliente realmente quer.

\subsection{Desperdícios no Lean Manufacturing}

Na concepção de Campos (1996), desperdício é o gasto de todo e qualquer recurso (matéria prima, tempo, energia, processo, entre outros) que não seja estritamente necessária para a produção de determinado produto, ou prestação de serviço. $\mathrm{Na}$ manufatura enxuta, este fator é assiduamente indesejado, pois 
aumenta o custo de produção de um produto ou execução de determinado serviço, sem que traga qualquer melhoria para o mesmo. Ohno (1997) classificou estas perdas em sete grupos:

Perda por superprodução: pode ser basicamente de dois tipos, superprodução por quantidade, sendo gerada por quantidade excessiva de produção, ou superprodução por antecipação, em que ocorre por antecipação da produção antes do momento necessário. Ghinato (2000) e Ohno (1997) afirmam que a perda por superprodução é a maior fonte de desperdício entre as demais, pois ela pode esconder as outras e é a mais difícil de ser eliminada.

Perda por transporte: de acordo com Ghinato (2000), o transporte é uma atividade que não agrega valor ao produto, então deve-se trabalhar incessantemente na redução deste desperdício, visto que $45 \%$ do tempo de fabricação de um item é gasto com transporte. Ainda afirma que, as melhorias mais significativas em relação a transporte são obtidas através de alterações da disposição da fábrica, que dispensem movimentações de material. Considerando-as como desperdícios de tempo e recursos, as atividades de transporte e movimentação devem ser eliminadas ou reduzidas ao mínimo. Elevada ênfase tem sido dada às técnicas de movimentação e armazenagem de materiais, mas deve ser ressaltada a importância em eliminar as necessidades de armazenamento, reduzindo os estoques, e eliminar a necessidade de movimentação, para que, se pense em racionalizar o transporte e a movimentação de materiais, que não puderem ser eliminadas.

Perda no processamento: são atividades de processamento desnecessárias para manter as características e funções básicas de qualidade, que o cliente requer do produto ou serviço Ghinato (2000), ou limitações técnicas nos processos resultando em redução da qualidade do produto (Shingo, 1996). Como exemplos de desperdício de processamento, tem-se o uso do jogo errado de ferramentas, sistemas ou procedimentos, geralmente quando uma abordagem mais simples pode ser mais efetiva. Slack et al. (2007) afirmam que, no próprio processo pode haver fontes de desperdício, pois algumas operações existem apenas em função do projeto inadequado de componentes ou manutenção deficiente, podendo assim ser eliminadas.

Perda por estoque: refere-se ao excesso de matériaprima, de estoque em processo ou de produtos acabados, causando lead times mais longos, obsolescência, custos de transporte, de armazenagem e atrasos. Estoques podem esconder outros problemas no sistema de produção, por exemplo, a fabricação de produtos defeituosos. Segundo Shingo (1996), a existência de estoques tem como raiz fundamental a falta de sincronia entre o prazo de entrega do pedido de compra e o período de produção. Para solucionar este problema é necessário estabelecer uma política que busque o nivelamento da quantidade, sincronização e o fluxo de operação de uma peça, bem como a adoção da produção em pequenos lotes. Estoque pode ser relacionado a desperdício pelo alto custo financeiro que o espaço e tempo utilizados por tal demandam. Segundo Ghinato (2000), o Sistema Toyota de Produção utiliza a estratégia de diminuição gradativa dos estoques intermediários, como uma forma de identificar outros problemas no sistema, escondidos por trás dos estoques.

Perda por produção de produtos defeituosos: Estas perdas se caracterizam pela fabricação de produtos não conformes, que não satisfazem os requisitos de projeto. Dentre todas as sete classes de perdas, a perda por fabricação de produtos defeituosos é a mais comum e visível, pois seus sinais se evidenciam no próprio produto ou serviço. A produção de peças, materiais em processamento e produtos acabados fora dos limites das especificações de projeto, resultam em refugo ou retrabalhos. Os retrabalhos geram custos adicionais como inspeção e reprocessamento, resultando em perdas no valor de venda. No caso de refugo, a empresa, além de perder matériaprima, perde também em processamento e custos diretos e indiretos. Se produtos não-conformes não forem detectados e chegarem ao cliente, esta perda terá proporções bem maiores, como o possível arranhão na imagem da empresa (Deon, 2001).

Perda por espera: esta perda é caracterizada por um intervalo de tempo no qual nenhum processamento está sendo realizado, tanto pelo operador como pela máquina, embora seus custos horários continuem sendo elevados. Longos períodos de ociosidade de pessoas, peças e informação, resultam em um fluxo pobre, bem como lead times longos. Para Ghinato (2000), existem três tipos de perdas por espera. A primeira é a perda por espera no processo, onde o lote inteiro espera o final de uma atividade que está sendo feita com o lote anterior. O segundo tipo é a perda por espera no lote, que é quanto, cada peça do lote espera para que todas as outras peças do lote também tenham sido processadas, para chegar até o consumidor. E a outra é perda por espera do operador, que é quando o operador tem que ficar monitorando o processamento de determinada máquina, enquanto poderia estar sendo mais útil exercendo atividades que agreguem valor ao produto final.

Perda por movimentação: há desperdício quando há movimentos de operadores desnecessários para a realização das atividades. Antunes (2008) propõe a meta de estabelecer padrões organizacionais para a execução eficaz das operações, como objetivo de minimização de perdas por movimentos desnecessários. Esta perda corresponde à desorganização do ambiente de trabalho, resultando em baixo desempenho dos aspectos ergonômicos e perda frequente de itens. Outro recurso que vem de encontro à eliminação deste desperdício é a automação, a qual possui um papel muito importante na simplificação dos movimentos.

\section{METODOLOGIA}

Com o intuito de esclarecer a situação atual de produção e buscar melhorias para alavancar a produtividade $\mathrm{e}$ lucratividade da empresa, foi inicialmente elaborado o mapa do fluxo de valor (MFV) do iogurte. Para isso, foram executados os seguintes procedimentos: selecionar a família de produtos a ser estudada (neste caso a família de iogurte); desenhar o mapa de estado atual; diagnóstico dos desperdícios; elaboração do mapa de estado futuro. Por fim, foram propostas as sugestões de melhoria.

As etapas da elaboração do mapa do estado atual foram executadas de acordo com Rother e Shook (2003). Na Figura 1 pode-se observar a estrutura de aplicação do mapeamento do fluxo de valor de um produto, destacando as etapas mais importantes do processo.

Neste trabalho partiu-se da premissa de que o produto alvo do estudo deveria ser o iogurte, devido à demanda da empresa em questão, a qual enxergou uma necessidade de otimização na fabricação deste produto visando maior 
competitividade de mercado e lucratividade. O objetivo seguinte foi selecionar os subconjuntos do iogurte que fariam parte da família de produtos a ser estudada.

Para atingir este objetivo, utilizou-se a ferramenta chamada Matriz Família de Produtos. Nesta matriz, incluiu-se iogurte de todos os sabores (e sem sabor), assim como todos os tamanhos de recipientes $(860 \mathrm{~g}, 185 \mathrm{~g}, 120 \mathrm{~g}$ e $13 \mathrm{~kg})$. De acordo com o agrupamento da matriz, definiu-se que todos os subconjuntos supracitados fariam parte da família de produtos, visto que os sabores diferentes de iogurte possuem exatamente o mesmo procedimento de produção, alterando apenas o sabor da polpa a ser adicionado. No que diz respeito aos tamanhos diferentes de recipientes, um mesmo lote de produção inclui todos os tamanhos do produto final, e não é feito de maneira individualizada, com lotes de fabricação para cada tamanho de embalagem. Desta maneira, todos os produtos finais foram considerados como "unidades", independente dos seus volumes. A Figura 2 representa a linha de distribuição dos produtos para melhor visualização do processo.

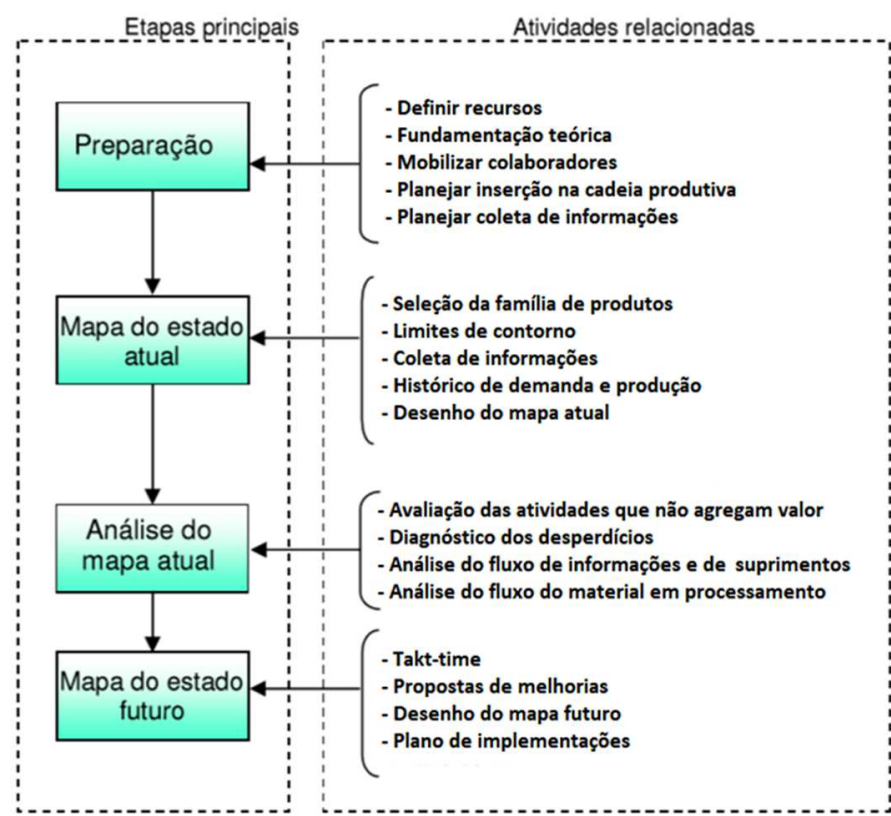

Figura 1 - Estrutura de aplicação do mapeamento de fluxo de valor (Kappes, 2011).

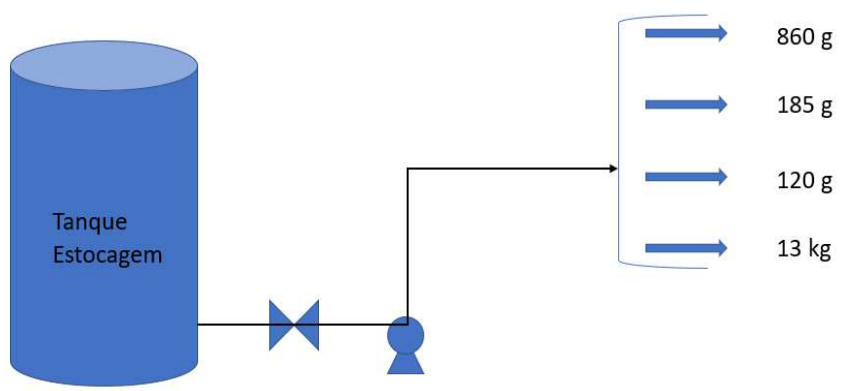

Figura 2 - Linha de distribuição dos produtos.

Ao final desta etapa constatou-se que a família de produtos selecionada apresenta uma linha de produção com grande potencial para implementação de melhorias, visto que contém muitos processos subsequentes, que funcionam durante 6 turnos seguidos de $4 \mathrm{~h}$ cada, utilizando diversos equipamentos diferentes.

Os tradicionais mapas de fluxo de valor são concebidos a partir de uma exposição visual da situação atual de uma família de produtos selecionada, são registradas informações do processo a fim de se obter os tempos de agregação de valor, e é realizada uma contagem do estoque a fim de se obter o lead time total. Tal metodologia caracteriza-se por uma abordagem estática do fluxo de valor, já que o mapa é exibido em função de um tempo único.

A fim de representar o fluxo de valor do iogurte, foi necessário seguir o caminho percorrido pelo lote, cronometrando-se todos os tempos dos processos e de atravessamento na linha de produção. Assim, as esperas entre os processos foram cronometradas ao longo da cadeia dos processos para um mesmo lote, conforme mostra a Figura 3, onde todas as etapas que formam o lead time são mostradas para um mesmo lote, em tempos diferentes. Desta forma, caracterizase a visualização do fluxo de materiais como uma abordagem dinâmica.

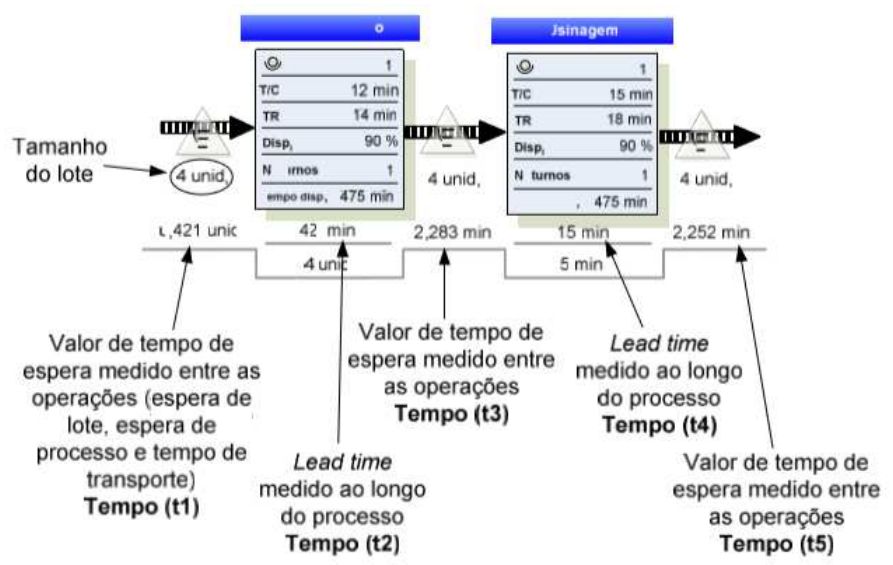

Figura 3 - Exemplo de abordagem dinâmica em um mapa de fluxo de valor (Kappes 2011).

O MFV foi elaborado com a utilização do software Excel $^{\odot}$. Para o desenvolvimento do mesmo, foi necessária observação de perto de todos os processos, com coleta de informações in loco. Foram coletadas as informações necessárias para a construção do mapa do estado atual: tempo de troca; disponibilidade; tempo de agregação de valor; histórico de demanda; número de colaboradores; tempo disponível de trabalho; estoques; número de variantes de produto da família; tempo de cada processo; frequências de pedidos e entregas.

As informações de tempo de troca, tempo de ciclo de cada processo na linha, tempo de estoque em cada etapa foram cronometrados e foram obtidas cinco amostras de cada operação para então, definir os lead times, como as médias das amostras de seu respectivo processo. Com estes lead times, foram calculados os tempos de ciclo, tempo total de processamento, tempo de atividades que não agregam valor e o lead time de produção. Os tempos de ciclo de cada processo foram calculados a partir da Equação 1. O tempo total de processamento foi calculado de acordo com a Equação 2:

$\mathrm{TC}=\frac{\text { tempo de processamento }[\mathrm{s}]}{\text { quantidade de produtos em processamento }[\mathrm{s}]}$

$\mathrm{AV}=\sum_{\mathrm{i}}^{\mathrm{n}} \mathrm{AVi}=\mathrm{AV} 1+\mathrm{AV} 2+\mathrm{AV} 3+\cdots+\mathrm{AVn}$

onde AV [s] corresponde as atividades que agregam valor.

Já para o tempo de atividades que não agregam valor calculou-se utilizando a Equação 3 e o lead time da produção foi 
determinado pela Equação 4.

$\mathrm{NAV}=\sum_{\mathrm{i}}^{\mathrm{n}} \mathrm{NAVi}=\mathrm{NAV} 1+\mathrm{NAV} 2+\cdots+\mathrm{NAVn}$

lead time de produção $=A V+N A V$

onde NAV [s] corresponde as atividades que não agregam valor.

Para recolher as informações de disponibilidade de máquinas, demanda de clientes, frequência de compras e pedidos, frequência de produção, quantidade de produção e demais variáveis, foram realizadas entrevistas com responsáveis por seus respectivos setores (setores de manutenção, de vendas, de produção ou expedição). Outras variáveis (como número de operadores em cada processo, tempo disponível de trabalho, logística e sequenciamento das atividades de produção) foram obtidas via observação e acompanhamento de toda a cadeia produtiva do iogurte.

A construção do mapa do estado atual, foi embasada pelo trabalho de Rother \& Shook (2003), seguindo-se as recomendações destes autores, elaborar o mapa de estado atual e utilizar os ícones padrões de fluxo de materiais, fluxo de informações, e os ícones gerais recomentados (Figura 3).

Para identificar os desperdícios presentes na manufatura do iogurte foi realizada análise crítica sobre toda a cadeia de produção do produto, baseando-se nos sete tipos de perdas previstos pelo pensamento enxuto. É importante frisar que, se acompanhou todos os processos do mesmo lote de produção e analisada a completa cadeia de produção de doze lotes de iogurte (considerando 6 turnos com duração de $4 \mathrm{~h}$ cada).

Por fim, foram determinadas as causas dos desperdícios e elaborado o mapa do estado futuro que, de acordo com Rother e Shook (2003), é um desenho da situação que se deseja ser alcançada pela empresa. A partir do mapa de estado futuro, foram identificadas as oportunidades de melhorias no fluxo dos processos. Estabeleceu-se um plano de ação para implantar as melhorias e apresentado como sugestão à empresa.

\section{RESULTADOS}

A Figura 4 apresenta o mapa do estado atual referente à família de produtos do iogurte, o qual proporciona uma visão ampla do fluxo de materiais e informações, do pedido do cliente, chegada de matéria-prima até a obtenção do produto acabado. $\mathrm{O}$ fluxo de produção inicia com o fornecimento e armazenamento das matérias-primas, que em seguida são processados e empurradas na linha de produção (Figura 4). Nota-se que cada matéria prima é utilizada diferentes etapas da cadeia de produção. Como observado, o leite é a principal matéria-prima do iogurte, tanto em questão de relação de volume do produto (comparado aos outros ingredientes). Desta maneira a linha do tempo abrange desde a primeira estocagem para posterior processamento do leite, até a expedição do produto.

Analisando a linha do tempo (Figura 4), ao somar os tempos das atividades que agregam valor ao produto (ou tempo de processamento) obteve-se tempo de 987 min (16,45 h). Já o somatório do tempo das atividades que não agregam valor atingiu $8549 \mathrm{~min}(142,5 \mathrm{~h})$, o que pode ser considerado um tempo demasiadamente elevado considerando-se o tempo de AV (aproximadamente $860 \%$ do valor). Ao somar o tempo de processamento (ou atividades que agregam valor) com o tempo que não agrega valor ao produto, chega-se no lead time total de produção de 9.536 min (158,9 h). Desta maneira, o tempo de processamento ocupa somente cerca de $10 \%$ do lead time de produção.

É importante destacar que o fornecimento diário de um volume médio de 4.0001 de leite é destinado exclusivamente para a produção de iogurte. Analogamente, o fornecimento de açúcar, polpas de frutas e caixas de papelão são realizados semanalmente. $\mathrm{O}$ controle de produção é feito através de uma programação semanal, e a comunicação entre o MRP e todas as etapas da cadeia de produção se dá através de um cartaz afixado em uma das paredes do chão de fábrica, informando aos funcionários qual e que quantidade produto deve-se produzir diariamente.

Foi constatado que um dos principais gargalos de produção do iogurte é o fornecimento de leite na região em que se localiza a empresa. Obviamente o fornecedor não pode estar a uma distância muito longa em relação à empresa. Isto por causa da alta perecividade do leite principalmente antes de ser resfriado (visto que os caminhões-tanque de recolhimento de leite não são refrigerados). Outro motivo para que o transporte da matéria-prima não possa demorar é a demanda diária de matéria-prima na empresa. Dependendo do tempo gasto pela rota torna-se inviável o transporte para uma alta frequência de movimentação, como neste caso. Mesmo recebendo aproximadamente 30.0001 de leite todos os dias, este suprimento é compartilhado para a produção de toda a gama do mix de produtos da empresa. Através da elaboração do mapa do estado atual foram contatados 5 dos 7 desperdícios abordados pelo lean manufacturing:

A perda por superprodução ocorre de maneira bastante significante com alguma frequência na empresa, quando por algum motivo há um déficit na demanda dos clientes em relação à produção, e o produto final alcança quinze dias estocado à espera da expedição (entre as caixas de envase e expedição, Fig. 10). Considerando que os produtos de laticínios possuem um período de validade curto, estes produtos não são mais aceitos no mercado, fazendo a empresa perder todo o lote de produtos finalizados, gerando um grande prejuízo financeiro.

A perda por transporte ocorre significativamente quando o iogurte engarrafado é transportado da área de envase (detalhe do processo de envase, Figura 10) para o local onde será encaixotado - na cadeia de produção do iogurte o material é todo transportado por dutos entre tanques durante os processos submetidos até o envase do produto, antes disso as perdas por transporte não são significativas. Posteriormente o produto encaixotado é movido novamente para ser posicionado em paletes e, na sequência, é transportado para a câmara fria onde fica estocado até a expedição. Por fim há o transporte do produto até o cliente. Esta é uma atividade que apesar de não agregar valor ao produto, é necessária. Deve-se então otimizá-las para que desperdice o mínimo possível.

No caso da perda por processamento, ao avaliar o mapa de estado atual, pode-se notar que uma das principais fontes de desperdício é a fase de encaixotamento dos produtos, em que são gastos muitos recursos como mão-de-obra, tempo, espaço (vide Figura. 10, são gastos 2 h, e 2 funcionários somente neste processo). Este tipo de desperdício se enquadra na perda por processamento, sendo uma atividade desnecessária para manter as características e funções básicas de qualidade que o cliente requer do produto. 


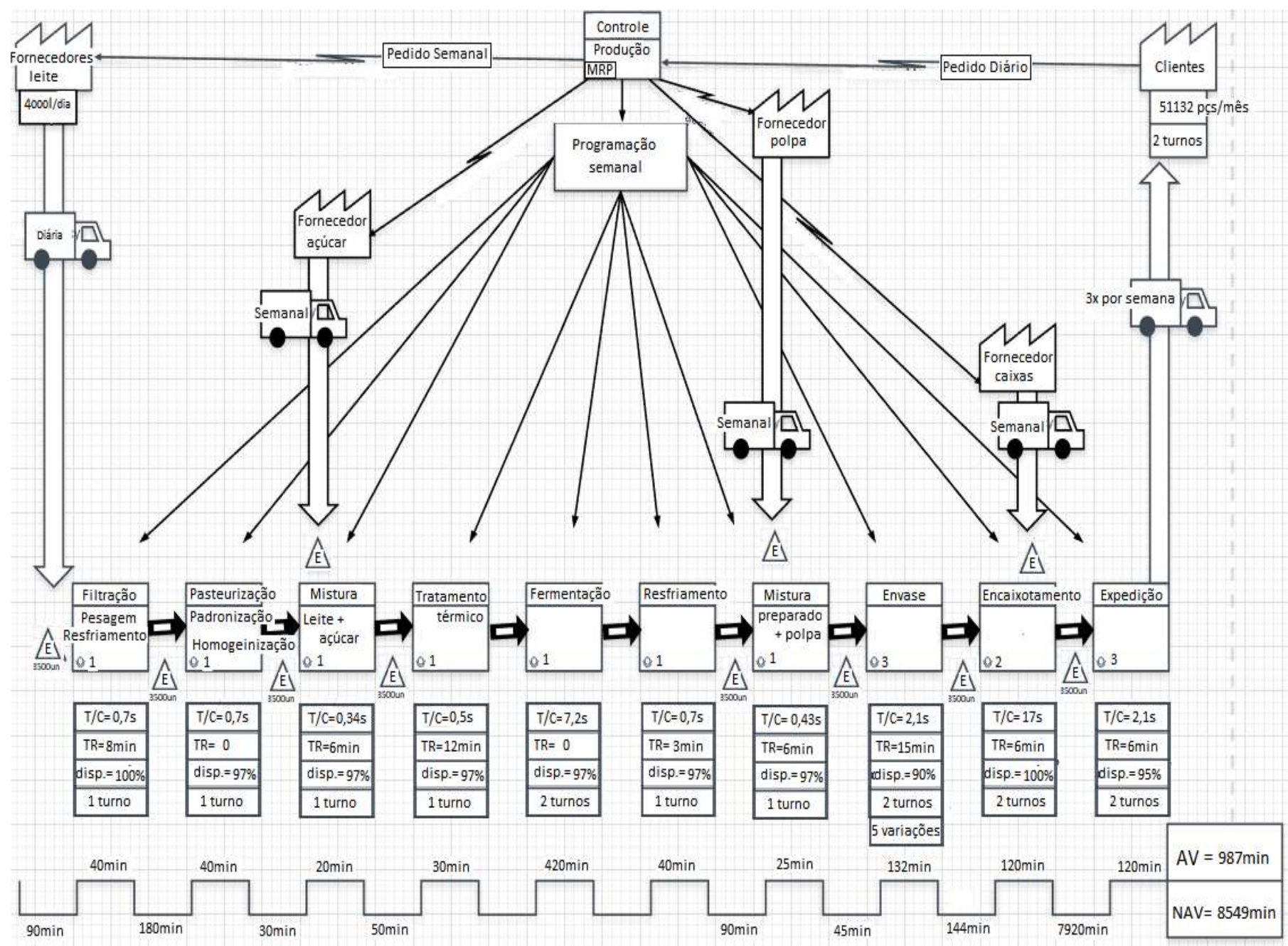

Figura 4 - Mapa do Estado Atual.

A maior fonte de desperdícios observada na produção do iogurte é a perda por estoque. Com o auxílio do mapa de estado atual, pode-se notar que o tempo em que o material fica estocado durante a produção de um lote é aproximadamente oito vezes maior do que o tempo de processamento do mesmo lote. O mapa expõe, a partir de seus dados, que o tempo de estocagem ocupa em torno de $90 \%$ do lead time total de produção. A etapa de estocagem que mais influencia no tempo total é o estoque do produto final, entre as caixas de encaixotamento e expedição, sendo que somente esta etapa ocupa cerca de $80 \%$ do lead time total de produção.

Outras perdas por estoque significativas, porém menores, são os tempos gastos de estocagem nos tanques de recepção do leite (matéria-prima), até ser iniciado o processo de pasteurização, representados pelos dois primeiros triângulos no mapa de estado atual. Gasta-se em torno de 270 min nestas etapas somadas, visto que o fornecimento diário de leite se dá durante um longo período de tempo, já que cada caminhão realiza uma rota diferente por isso chegam em horários diferentes. Como vários caminhões transportam e descarregam cargas de leite todos os dias, há uma demora de cerca de 310 min desde a chegada do primeiro caminhão até começar o processamento em fluxo, que seria na pasteurização do leite.
Gasta-se em torno de 234 min na limpeza das instalações e dos equipamentos antes da mistura da polpa e após o envase. Estes produtos ficam estocados à espera da próxima operação, enquanto os funcionários estão realizando a limpeza. Há ainda um agravante nesta atividade, sendo que os canais de escoamento de água no chão (ralos) não foram posicionados de maneira correta durante a construção da estrutura, de modo que os ralos não correspondem com as posições de caídas de água no chão da fábrica. Desta forma, desperdiça-se tempo limpando o chão, pelo fato de os colaboradores ficarem induzindo a água para escoar para o lugar certo.

Durante as observações no chão de fábrica, foi possível presenciar diversas ocasiões onde se cometia desperdício por produção de produtos defeituosos. Nestas ocasiões, houveram diversos erros nos processos de envase: a garrafa não estava posicionada da forma correta no momento em que o produto foi injetado, dosagem incorreta no envase, ou erros na selagem das tampas das garrafas, onde a tampa não fica bem fixada e libera iogurte do seu interior. Houveram também erros na pintura da embalagem, ou produtos que foram expedidos sem a estampa de datas de fabricação e validade. Foi feita uma estimativa fazendo uma média da contagem de produtos defeituosos durante o período de observação, e chegou-se num valor aproximado de 
13 unidades por turno de $4 \mathrm{~h}$. Além dos defeitos, houve relatos dos colaboradores que, mesmo que com baixa frequência, há erros nos processos de tratamento térmico, fermentação e resfriamento, como também há dosagem indevida de ingredientes, fazendo com que todo o lote seja perdido, significando retrabalho, com perda de materiais, mão-de-obra, uso de equipamentos, energia, entre outros.

Considerando-se os tipos de perdas por espera e por movimentação definidos pelo pensamento enxuto, foi constatado que os mesmos são desprezíveis no que se refere à produção de iogurte da empresa em questão.

\subsection{Sugestões de melhorias}

Atualmente a produção de um lote de iogurte começa com a chegada do leite na parte da tarde de um dia normal de trabalho, geralmente a partir das 13:00 h. Inicia-se então o processamento da matéria-prima, que vai fluindo de processo em processo, até chegar em uma etapa de produção onde o produto se encontra engarrafado e encaixotado (ao observar pelo mapa a etapa referida é a caixa de encaixotamento, Fig. 10). Tem-se que o tempo médio desde a chegada do leite até o produto encaixotado é de aproximadamente $25 \mathrm{~h}$. Em contrapartida, o tempo a partir do produto encaixotado até chegar aos clientes é em média, de aproximadamente $136 \mathrm{~h}$. Para o estado futuro, deseja-se reduzir ambos os intervalos de tempo, sendo o segundo obviamente mais crítico e que contém alguns obstáculos. Inicialmente será focado no primeiro intervalo de tempo, para a sugestão de melhorias para reduzir o tempo de produção desde a chegada do leite até o produto embalado.

Redução de tempo de produção: a finalidade de se reduzir o tempo de produção neste caso é pela tentativa de igualar, ou pelo menos aproximar, o tempo de ciclo de produção com o takt time. Isto é feito com a intenção de sincronizar o ritmo da produção com o ritmo das vendas e calculado pela Equação 5:

takt time $=\frac{14.400[s]}{1.065[\text { peças }]}=13,5[s / p c ̧]$

Melhorias no estoque: pode-se reduzir o primeiro estoque ao controlar o horário que cada caminhão de leite sai para realizar a rota do dia e chega para descarregar o leite. Devese utilizar a previsão do tempo de cada rota de maneira que cheguem em horários diferentes, mantendo um intervalo de tempo entre cada caminhão. Desta maneira, é possível reduzir ou até mesmo eliminar a espera ou fila entre eles ao descarregar a matéria-prima. Além disso, sabendo-se o horário que cada um vai chegar, pode-se deixar o equipamento e mão-de-obra preparados no horário correto para reduzir ao máximo o tempo de espera antes do primeiro processo (que é a filtração). Destaca-se que programas de Sistemas de Posicionamento Global (GPS) conseguem fazer uma previsão de rota bastante confiável ao utilizar informações em tempo real sobre trânsito e outras variáveis de interesse.

Em relação ao segundo estoque, onde é gasto em torno de 180 min desnecessariamente, deve-se também utilizar uma logística para planejar a programação dos horários de saída e chegada de cada caminhão e sua respectiva rota do dia. Deve-se controlar a chegada dos caminhões em intervalos diferentes para que não haja fila e também controlar a rota de modo que o leite possa chegar na fábrica apenas na hora em que ele seja requisitado (como na véspera do início da produção de determinado produto). Pode-se notar que neste caso, mesmo que o estudo seja sobre a produção do iogurte, é necessário um reajuste no sistema de produção de todo o mix de produtos, visto que a matéria-prima é compartilhada por todos os produtos. Por outro lado, todos os sistemas de produção também serão agraciados com a redução de desperdício. Sugere-se também aplicar um sistema kanban com supermercado para o fornecimento de caixas de papelão com o intuito de reduzir o tempo de estoque de embalagem. Da mesma maneira utiliza-se supermercado de matéria prima para a obtenção de polpa de frutas.

Eliminação de estoques entre processos: para eliminar os estoques seguintes até a fermentação, deve ser alocado mais um funcionário nestas etapas para que eles consigam manter um fluxo constante do material até o tanque de fermentação. Para isso, enquanto um operador está realizando as atividades de processamento, o outro operador deve estar o auxiliando quando necessário e preparando os equipamentos e procedimentos da próxima etapa da produção, para evitar a parada entre processos.

$\mathrm{O}$ estoque que antecede a mistura do preparado com a polpa e o estoque após o processo de envase devem ser otimizados, pois desperdiçam muito tempo devido a limpeza das instalações e equipamentos. Para reduzir estes tempos, dois cenários são propostos: o primeiro cenário sugere alocar funcionários especificamente para a limpeza do chão de fábrica e equipamentos, deixando o operário responsável pela produção livre para seguir com o próximo processo sem espera; o segundo sugere a possível flexibilidade de funcionários trabalharem em setores de produtos diferentes num mesmo dia ou turno. Desta maneira, pode-se fazer uma sincronia de produção de produtos diferentes ao mesmo tempo, encaixando etapas de cada um onde é necessário mais ou menos trabalhadores de forma a otimizar a mão-de-obra disponível reduzindo o tempo de produção dos produtos.

Redução de estoque de produto acabado: de acordo com dados de histórico de pedidos e histórico de produção, foi possível chegar numa média de 5,5 dias que o produto fica estocado. É um tempo absurdamente grande, sendo mais de sete vezes maior do que o tempo de processamento do produto e ocupando cerca de $80 \%$ do lead time total de produção. Devese considerar também que o produto precisa obrigatoriamente permanecer estocado aproximadamente $48 \mathrm{~h}$ antes de ser expedido, devido à verificação da existência de bolor e levedura (que é feita com amostras de todos os lotes que são produzidos na empresa).

Desta maneira, sugere-se que seja utilizada uma linha first in first out (FIFO) entre os processos de encaixotamento e expedição. Segundo Rother e Shook (2003), a linha FIFO funciona como um canalete que pode armazenar uma quantidade limitada de estoque. Assim, entre dois processos, significa que para um produto entrar na linha FIFO de um lado, deve sair um produto do outro lado. A limitação da quantidade deste estoque deve ser projetada com base no histórico e previsão de demanda dos clientes, visando reduzir ao máximo o tempo de produto final estocado para o mais próximo possível de 48 h, que é o mínimo permitido, e ao mesmo tempo ter a capacidade de absorver as flutuações de mercado. Mesmo sabendo-se que é inviável transformar a cadeia em produção 'puxada', pelo fato de o iogurte ser produzido em lotes, esta implementação da linha FIFO faz com que o processo de encaixotamento puxe a produção utilizando a linha como 
indicador de necessidade de produção, para que informe ao processo de pasteurização a quantidade a ser produzida e o momento certo para iniciar a produção.

Melhoria no processamento: para reduzir o desperdício no processamento presente na etapa de encaixotamento, sugerese a aquisição de uma máquina que fecha e sela as caixas de maneira automatizada. Precisando-se de um operador apenas para o posicionamento das caixas. Desta maneira, estima-se que o tempo do processo de encaixotamento se reduziria mais de $50 \%$, com a aplicação de um investimento muito baixo.

Melhoria no transporte: para reduzir os desperdícios por transporte cometidos sugere-se alterar o posicionamento do processo de encaixotamento no layout da fábrica (visto que não é necessário reposicionamento de nenhum equipamento, apenas do funcionário e das caixas) de modo que o processo de encaixotamento ocorra onde o produto envasado fica posicionado, evitando transporte entre envase e encaixotamento, sendo movido apenas em direção à câmara fria.

No que diz respeito ao desperdício no transporte do leite, apesar de ser necessário, pode ser otimizado ao aplicar a logística dos horários de caminhões para que cheguem somente quando o leite é necessitado. Desta maneira, além de reduzir as perdas no estoque, o transporte desnecessário de leite também é reduzido significativamente, uma vez que o material será transportado somente quando requisitado.

Melhoria da superprodução: de acordo com a sugestão de implementação de uma linha FIFO entre o encaixotamento e a expedição, como discutido anteriormente, obtém-se um indicador da necessidade de produção, se tornando numa ferramenta utilizada também para reduzir a diferença entre demanda e produção, combatendo assim as perdas por superprodução.

\subsection{Mapa do Estado Futuro}

Após a finalização da fase de mapeamento do estado atual e análise de seus desperdícios, elaborou-se o mapa do estado futuro do fluxo de valor no nível porta-a-porta do iogurte (Figura 5). O mapa do estado futuro representa uma projeção do estado ideal sob a ótica dos princípios da manufatura enxuta. A partir das implementações sugeridas, foi feita uma análise do procedimento prático de cada atividade considerando as melhorias já implementadas, para que seja mensurado o leadtime de cada processo e estoque com a maior precisão possível.

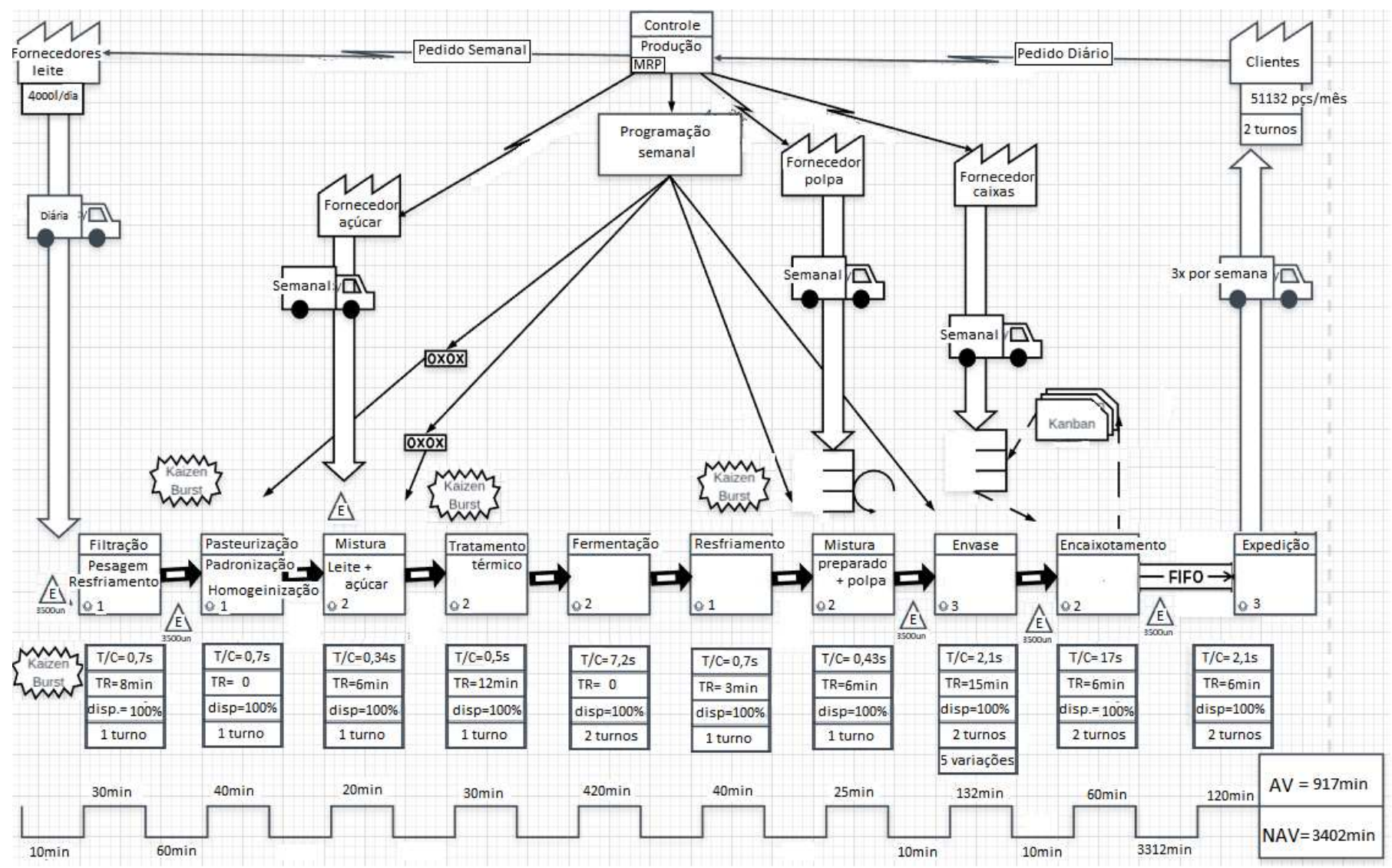

Figura 4 - Mapa do estado futuro.

A seguir são feitas algumas ponderações acerca do mapa do estado futuro do iogurte e seus resultados com relação a melhorias aplicadas ao mapa do estado atual:

- Redução do primeiro estoque de matéria-prima de 90 min para $10 \mathrm{~min}$, ou seja, $11,1 \%$ de seu valor inicial, devido à logística de rota de fornecimento da matéria prima;

- Redução do tempo dos processos de filtração, pesagem e resfriamento (primeira caixa de processos do mapa) de
40 min para 30 min, devido a preparação meticulosa de funcionários e equipamentos para estar tudo pronto quando o caminhão chegar para descarregar o leite;

- Redução do segundo estoque de $180 \mathrm{~min}$ para $60 \mathrm{~min}$, $33,3 \%$ do valor inicial;

- Eliminação dos estoques que antecedem os processos de mistura do açúcar e tratamento térmico, reduzindo assim 80 min do lead time de produção;

- Eliminação do estoque do material promovendo um fluxo contínuo entre o resfriamento e a mistura do 
preparado com a polpa de fruta;

- Redução dos tempos de espera do lote em processamento (estoque) que antecedem o envase e o encaixotamento, ao solucionar o problema que o tempo de limpeza trazia à eficiência, reduzindo os tempos somados de $189 \mathrm{~min}$ para 20 min, implicando numa redução de 169 min do lead time de produção;

- Redução do tempo de encaixotamento de 120 min para 60 min, devido à utilização da máquina seladora;

- Redução do tempo de estoque do produto acabado, com o auxílio da ferramenta FIFO, que foi de 7.920 min para $3.312 \mathrm{~min}$, resultando em uma eliminação de $4.608 \mathrm{~min}$ do lead time de produção.

Desta forma, com a aplicação das sugestões de melhorias, pode-se esperar a melhora na produtividade de acordo com a grande redução de tempo de atividades que não agregam valor, que foi de 60\% (8.549 min para $3.402 \mathrm{~min}$ ). Também foi possível reduzir de maneira significativa o tempo de processamento do produto, cerca de $7 \%$. Assim, o lead-time de produção a ser atingido na situação futura foi de apenas $45 \%$ do lead time atual, ou seja, foi reduzido de $9.536 \mathrm{~min}$ para 4.319 $\min$.

\section{CONCLUSÕES}

Neste trabalho foi efetuado o mapeamento do fluxo de valor do iogurte em uma empresa de laticínios da Zona da Mata/MG. Elaborou-se o mapa do estado atual e o mapa do estado futuro para este produto. Com isto, conclui-se que:

- A aplicação do MFV permitiu constatar 5 tipos de desperdícios significativos na produção do iogurte, dentre os 7 previstos no pensamento enxuto. As perdas por espera e movimentação, apesar de identificadas pelo autor durante a produção, foram consideradas desprezíveis para o escopo do trabalho em questão;

- Foram sugeridas implementações efetivas para atacar 4 tipos de desperdícios. Os desperdícios por estoque, processamento, transporte e superprodução foram reduzidos, de modo que as perdas por estoque sofreram reduções mais significativas, com redução em torno de $60 \%$ no tempo total. Com a implementação de uma linha FIFO, pode-se reduzir consideravelmente o tempo de estoque de produto acabado e assim reduzir o lead time de produção do iogurte.

- A aplicação do MFV com a representação dos lead times corridos mostrou um grande potencial para visualizar o estado atual, e para a criação de um ambiente favorável através do conjunto de técnicas e ferramentas enxutas. Desta maneira, o presente trabalho engrandece a importância da utilização do MFV em diferentes setores da indústria visando sempre a otimização da produção.

- Uma implementação profunda das ferramentas do lean manufacturing em uma empresa é um processo bastante complexo e que demanda planejamento e esforço de todos os colaboradores. Apesar disto, demonstrou-se que é possível otimizar a produtividade de determinada empresa de maneira grandiosa ao implantar melhorias baseadas na produção enxuta, mas que sejam até certo ponto simples e de baixo investimento, mantendo o sistema empurrado de produção.

- Além da redução no lead time de manufatura através das melhorias propostas, este trabalho possibilitou a agregação de valor cultural aos operadores e supervisores, pois no processo de análise e questionamento da razão pela qual a sequência das operações e o layout do "chão-de-fábrica" estavam ordenados de tal forma, houve muitas quebras de paradigmas, identificando-se fluxos ineficazes e processos desnecessários na manufatura. Tais aspectos descaracterizaram um antigo ambiente de acomodação, e trouxeram a cultura de que os fluxos e processos podem ser simplificados, e podem ser melhorados continuamente. Esses colaboradores passaram a visualizar os processos no âmbito de fluxo de valor, obtendo uma visão sistêmica, passando a aplicar estes atributos em fluxos de outros produtos da organização.

\section{REFERÊNCIAS}

ANTUNES JÚNIOR, J. A. V.; KLIPPEL, M. Análise crítica do inter-relacionamento das perdas e dos subsistemas do sistema Toyota de Produção. Em Encontro nacional de Engenharia de Produção, 2008, Curitiba.

CAMPOS, V. F. Controle da Qualidade Total (no estilo Japonês). Belo Horizonte: Fundação Christiano Ottoni, 1996.

DEON, A. M. Medição do custo das perdas associadas ao processo produtivo de fabricação de celulose e papel. 191 p. Dissertação (Mestrado em Engenharia de Produção) Universidade Federal de Santa Catarina, SC, 2001.

GHINATO, P. Produção \& Competitividade: Aplicações e Inovações, Recife: Adiel T. de Almeida \& Fernando M. C. Souza, 2000.

IMTIAZ G.; IBRAHIM A.R. Lean Production System to Enhance Performance in Operations: An Empirical Study of Malaysian Construction Industry. 2007, Michigan, USA, In. Proceedings IGLC.

KAPPES, J. J. Aplicação dos conceitos de manufatura enxuta na produção de bens de capital sob encomenda um estudo de caso de um produto do setor metalmecânico. $200 \mathrm{f}$. Dissertação (Mestrado em Engenharia Mecânica) Universidade Federal de Santa Catariana, SC, 2011.

NAZARENO, R. R. Desenvolvimento e aplicação de um método para a implementação de sistemas de produção enxuta. Dissertação (Mestrado em Engenharia de Produção), São Carlos, 2003.

OHNO, T. O. Sistema Toyota de Produção: além da produção em larga escala. 1 ed. Porto Alegre: Artes Médicas, 1997.

RENTES, A. F.; CARPINETTI, L. C. R.; AKEN, E. M. Measurement system development process: a pilot application and recommendations. Boston, 2002. In: Proceedings of Performance Measurement Association, p. 487-494, 2002.

ROCHA, C. Avaliação do impacto da implementação de ferramentas do Lean Manufacturing e técnicas de gestão de estoque nos principais processos envolvidos numa linha de usinagem. 104 f. Dissertação (Mestrado Profissional em Engenharia Civil) - Universidade Federal de Santa Catarina, SC, 2008.

ROTHER, M.; SHOOK, J. Aprendendo a enxergar - mapeando o fluxo de valor para agregar valor e eliminar o desperdício. São Paulo: Lean Institute Brasil, 2003.

SHINGO, S. O Sistema Toyota de Produção do ponto de vista 
da Engenharia de Produção, 2 ed. Porto Alegre, Artmed, 1996.

SILVA E. N.; SANTOS G. T. A aplicação dos conceitos do Sistema Toyota de Produção em uma empresa prestadora de serviços. Porto Alegre: LOOP/UFRGS, 2004.

SLACK, N. et al. Administração da produção. São Paulo: Atlas, 1997.

WOMACK, J. P.; JONES, D. T.; ROOS, D. A Máquina que
Mudou o Mundo, 5 ed. Rio de Janeiro: Campus Ltda, 1992.

WOMACK, J. P.; JONES, D. T. A mentalidade enxuta nas empresas". 5. ed. Rio de Janeiro: Campus Ltda, 1998.

WOMACK, J. P.; JONES, D. T. A Mentalidade enxuta nas empresas. $6^{\mathrm{a}}$ ed. Rio de Janeiro: Campus, 2004. 